Derecho \& Realidad

Núm. 23 • I semestre de 2014

Facultad de Derecho y Ciencias Sociales, UPTC

ISSN: 1692-3936

\title{
Los derechos sociales en la era tecnológica. Especial referencia al derecho a la protección de la salud*
}

Social rights in the technological era. Particular reference to the right to protection of health

Marta León Alonso**

\section{Resumen}

La autora busca superar la división entre derechos de libertad y derechos sociales, introduciendo unas variables que juegan en favor de estos últimos cuando quiera que existan principios como la necesidad y la proporcionalidad. En medio de las crisis recientes, resulta un artículo aleccionador que invita a repensar los DESC.

Palabras clave

Derechos sociales, justicia social.

* Este trabajo forma parte de una investigación más amplia que en estos momentos estoy llevando a cabo en la Universidad de Salamanca (España).

** Profesora de Derecho Constitucional, Universidad de Salamanca (España).

Correo electrónico: martala@usal.es 


\section{Abstract}

The author seeks to overcome the division between freedom rights and social rights by introducing some variables that play in favor of the latter whenever there are principles such as the need and proportionality. Amid the recent crisis, it is a sobering article that invites us to rethink the economic, social and cultural rights.

\section{Key words \\ Social rights, social justice.}


Derecho y Realidad

\section{Los derechos sociales como elementos estructurales del Estado social y democrático de derecho}

\subsection{Los precedentes del Estado social}

La fórmula del Estado social sintetiza el final de la separación entre la sociedad civil y el Estado y el establecimiento de un nuevo marco de relaciones en el que los poderes públicos asumen funciones que hasta el momento les habían sido vedadas. Así mismo, la transformación del Estado ha tenido como consecuencia la modificación del contenido de las Constituciones: la nueva actividad estatal ha hecho que en ellas se incluyeran preceptos destinados a regular su intervención en la economía y en el orden social.

Ahora bien, la formación del Estado social no responde, según indica Antonio Baldassarre, a un planteamiento teórico e ideológico concreto ${ }^{1}$. El Estado social constituye la pretensión de dar respuesta, más allá del Estado liberal, a dos fenómenos de la época: la industrialización y la democratización. En este sentido, y según palabras del autor apenas citado, "[...] lo Stato sociale è la risposta politicocostituzionale alla crescente e obiettiva insicurezza sociale, che costituisce il sottoprodotto [...] sia degli squilibri di potere [...] sia dell'instabilità dei valori insita nelle accelerate dinamiche culturali" ${ }^{2}$.

En efecto, como señala el maestro García-Pelayo (1995) el Estado social supuso, históricamente, el intento de adaptación del Estado liberal burgués a las condiciones sociales de la civilización industrial y post-industrial, con sus nuevos y complejos problemas, pero, también con sus posibilidades técnicas, económicas y organizativas para afrontarlos.

Para el profesor Elías Díaz el Estado social nace con el propósito de solucionar los problemas de la sociedad industrial frente a la incapacidad de los esquemas e instituciones tradicionales del Estado de derecho liberal, siendo el individualismo y el abstencionismo estatal los elementos que precisaban una mayor revisión (1988, p. 84-85).

No obstante, no hay que olvidar que el Estado social toma como base formal para su implantación y desarrollo el Estado de Derecho liberal. Recordemos, brevemente, por razones meramente expositivas y sin la intención de ser exhaustivos, cómo el

\footnotetext{
No ocurrirá lo mismo con el intento de desmantelamiento del Estado social que sí responde a planteamientos ideológicos determinados como veremos más adelante.

2 Vid. A. Baldassarre, voz "Diritti sociali", en Enciclopedia Giuridica Treccani (1989, p. 28 y sigs.), y años más tarde en Diritti della persona e valori costituzionali, (1997, p. 123 a 222).
} 
origen histórico del Estado de Derecho está relacionado con el liberalismo y con el ascenso político, a finales del siglo XVIII, de la burguesía, el llamado tiers état por Sièyes. El sistema socio-político del Antiguo Régimen, cimentado sobre la división en estamentos de todo el cuerpo social, es sustituido por un nuevo orden en el que se redefine la relación entre el Estado y la sociedad. La sociedad civil, integrada por la burguesía liberal, cuyo poder económico se ve favorecido por el desarrollo del tráfico mercantil, asume como nuevos valores la igualdad (jurídica), la propiedad y la libertad, rescatando al individuo de las rígidas estructuras corporativas del período anterior. El liberalismo propugna la existencia de un orden natural, fuera del control del Estado, fundado en la iniciativa privada que garantiza la prosperidad económica y el desarrollo social.

En este marco, el Estado, explica García-Pelayo (1995, p. 21 y 22), consiste en una organización racional, estructurada de forma jerárquica y con unos objetivos y valores: la garantía de la libertad, de la convivencia pacífica, de la seguridad y de la propiedad.

La racionalidad del Estado se manifiesta en el concepto de ley, como norma general y abstracta, en la división de poderes y en la organización burocrática de la Administración. La legitimidad del Estado de Derecho liberal se cimienta en el reconocimiento y garantía de un sistema de derechos y libertades, en el sometimiento de los poderes públicos al imperio de la ley y en el control jurisdiccional de sus actos. La sociedad, por su parte, se concibe como un orden espontáneo, dotado de racionalidad inmanente, expresada en leyes económicas y basada en una estructura horizontal. El Estado, como organización artificial, debe limitarse a garantizar las condiciones adecuadas para que se dé la armonía natural en la que se desarrolla la actividad de la sociedad civil.

Pero, coincidiendo con la irrupción en Europa del capitalismo, la situación social va a sufrir una serie de transformaciones que acaban con el mito de la armonía espontánea. Se produce una concentración de la producción y del capital, que desemboca en la formación de grandes monopolios financieros. Paralelamente al desarrollo fabril, se genera un proceso de depauperación de los estratos más desfavorecidos, el proletariado industrial y el excedente de la población rural. El éxodo rural, el crecimiento de las ciudades y la aparición de una masa ingente de trabajadores que viven de la venta de su fuerza de trabajo, modifican las relaciones sociales y los modos de vida. Se acaba con las formas autónomas y autárquicas de subsistencia. En palabras de Forsthoff, se abandona el espacio vital dominado, que es aquel del que el individuo puede disponer y del que obtiene las garantías básicas para su existencia, y se pasa a formar parte del espacio vital efectivo, en el que el hombre está supeditado a un trabajo, a un salario que le permite acceder a determinados bienes con el fin de asegurar un mínimo vital. Esta necesidad de 
utilizar bienes y servicios sobre los que no se tiene un dominio directo da lugar a la "menesterosidad social", que afecta, no sólo a las clases más desfavorecidas, sino también a los sectores más pudientes. Las sociedades, cada vez más conflictivas, son incapaces de autorregularse. Ante tal situación, la única vía es permitir la intervención del Estado y así intentar resolver los fallos del mercado.

El Estado se verá obligado a adoptar una serie de medidas (redistribución de la riqueza y prestaciones sociales) en aras de atenuar el conflicto social. De este modo, la realización de la "procura existencial" se convierte en la nueva función del Estado ${ }^{3}$.

\subsection{La constitucionalización del Estado social}

Los acontecimientos bélicos que se sucedieron en la primera mitad del siglo $\mathrm{XX}$ aceleraron la consolidación de la idea del Estado social. En efecto, las graves consecuencias políticas, económicas y sociales provocadas por las dos guerras mundiales hicieron más patente que nunca la necesidad de la intervención del Estado como única vía para superar la situación de crisis generalizada. Sin embargo, como explica García-Pelayo, la existencia misma del Estado estaba en cuestión. Si el Estado democrático liberal de Derecho quería mantener su vigencia, tenía que adaptar sus valores a las nuevas exigencias y añadir a sus objetivos los de la regulación permanente del sistema social. De ahí el interés existencial del Estado de proceder a la estructuración de la sociedad Si el Estado de Derecho quería subsistir tendría que disponer permanentemente de los aspectos sociales, económicos y culturales ${ }^{4}$.

$3 \quad$ Estas ideas se encuentran recogidas en varios pasajes de la obra de E. Forsthoff. Por primera en Die Verwaltung als Leistungsträger, en 1938, como recuerda el propio autor en El Estado de la sociedad industrial. El modelo de la República Federal de Alemania (1975, p. 120 y 121) y en Problemas constitucionales del Estado social, en W. Abendroth, E. Forsthoff, K. Doehring (1986, p. 47 y 48 ).

4 Cfr. García Pelayo (1995, p. 21 a 25). Sobre la crisis en la que estaba inmerso el Estado de derecho liberal también García Cotarelo (1990, p. 11 y ss) ha explicado el proceso de deslegitimación en el que estaba inmerso. En el marco del Estado liberal burgués, el Estado estaba legitimado para garantizar la seguridad, la justicia y las obras públicas. Sin embargo, cualquier otra función que se le atribuyera lo deslegitimaba, porque se entendía como un abuso de poder, como una injerencia en la sociedad civil. Señala Carcía Cotarelo como, paradójicamente, la situación de permanente conflicto bélico también contribuye a la deslegitimación del Estado, ya que pone en constante peligro la seguridad de la sociedad civil. Por otro lado, a partir de los años veinte del siglo pasado, al Estado no interventor se le comienzan a atribuir todas las culpas de la crisis económica. Por todos estos motivos, legítimo ya no se considera el Estado que se mantiene sólo como árbitro. Al contrario, legítimo es el Estado que canaliza los conflictos sociales. Lo que ocurre es que esta clase de intervención se hizo, en un primer momento, al margen del formalismo propio del Estado de Derecho. Los cambios Ilegarán al final de la II Guerra Mundial. El Estado tendrá que reflejar en su estructura jurídico-política las transformaciones que ha experimentado la sociedad. El Estado tendrá que articular un orden social y económico diferente. La nueva forma de legitimación del Estado se basa en mantener un régimen de libertades formales al mismo tiempo que avanza hacia la progresiva igualdad de los individuos. El Estado social de Derecho sería la síntesis de dos principios hasta ahora excluyentes: la libertad y la igualdad. 
En este sentido, la constitucionalización del Estado social va a suponer un cambio en la manera de entender las relaciones entre la sociedad y el Estado y una transformación en sus funciones.

Frente a las intervenciones legislativas de carácter coyuntural llevadas a cabo por los distintos gobiernos europeos durante el siglo XIX y primeras décadas del siglo $\mathrm{XX}$, la incorporación de la cláusula social a las Constituciones va a suponer que el Estado asuma la obligación permanente de promover el desarrollo social, económico y cultural de los ciudadanos.

Así, en las primeras décadas del siglo XX en Europa se redactan algunas Constituciones9 que contienen los principios del Estado social. Sin embargo, su desarrollo se verá truncado por el advenimiento de gobiernos totalitarios. Este fue el caso de la pionera Constitución de la República de Weimar de 1919 y de la Constitución española de 1931. Ambas normas incluían, además de los clásicos derechos de libertad, un amplio catálogo de derechos de índole social. No obstante, los preceptos de contenido social, dirigidos principalmente al legislador, resultaban de difícil aplicación, lo que imposibilitó, en un primer momento, el reconocimiento de su eficacia jurídica provocando su degradación a la categoría de simples recomendaciones socioeconómicas. Abendroth (1986, p. 19-20) nos recuerda que la propia jurisprudencia de Weimar transformó muy pronto las exigencias de tipo social de la Constitución de 1919 en fórmulas vacías de contenido al ser consideradas como programáticas, carentes de significación concreta y sin carácter vinculante para el legislador del Reich.

Frente a estos planteamientos, se escuchan algunas voces disidentes entre la doctrina constitucionalista de aquellos años. Hay que destacar la aportación al respecto de uno de los mayores juristas de la época. Se trata de Hermann Heller (1985, p. 283-301), quien en 1929 une por primera vez la idea del Estado social a la de Estado de derecho, acuñando la expresión Estado social de derecho. El autor alemán reivindica el Estado de derecho frente a la dictadura fascista e intenta dotarlo de un contenido social para atenuar las desigualdades a las que había conducido el Estado liberal. El concepto de Estado de derecho había pertenecido al acervo común de las ideas y no había sido puesto en discusión hasta el final de la Primera Guerra Mundial. En la era del capitalismo desarrollado el proletariado toma conciencia de sí mismo y comienza a hacer suya, en forma de democracia social, la democracia burguesa. Mediante partidos y sindicatos consigue participar en el legislativo y se equipara jurídica y políticamente a la burguesía. Por medio de la legislación, el más débil económicamente intenta poner trabas al económicamente más fuerte, exigiendo prestaciones sociales y desposeyéndolo de su propiedad. La burguesía ante esta situación se siente amenazada por un proletariado cada vez más organizado y comienza a renegar del Estado de derecho y de sus principios. La negación y el vaciamiento de la idea de Estado de 
Derecho y Realidad

derecho se producen porque el principio de igualdad de los asociados ante la ley se ha convertido en una concepción técnico-formalista. La igualdad ante la ley no significa la prohibición de la arbitrariedad para el legislador, sino que se refiere al momento de aplicar la norma por la Administración. Frente a este Estado formalista y ante las reivindicaciones populares, Heller propone extender el Estado material de derecho a todos. Es decir que las necesidades esenciales de todos estén atendidas y que se aplique la igualdad en la ley.

Finalizada la II Guerra Mundial, en la Ley Fundamental de Bonn de 1949, a diferencia de lo que se hizo en la Constitución de Weimar, no se incluyen normas que desarrollen el principio consagrado en su artículo 20.1 " “"La República Federal de Alemania es un Estado federal democrático y social" ". La razón de esta ausencia se debe al intento de evitar las dificultades que se derivaron de la falta de eficacia jurídica de los preceptos que contenían derechos sociales en la Constitución de 1919.

El debate doctrinal en torno al concepto y a la naturaleza del Estado social ha vivido momentos de especial intensidad sobre todo en Alemania ${ }^{5}$ en un tiempo en el que, como indica Forsthoff "la conciencia de la crisis del Estado de derecho es general y como una superación a dicha crisis se presenta la acomodación del Estado de derecho a las urgentes tareas sociales mediante una remodelación o reinterpretación del Estado de Derecho en tanto que Estado social de Derecho".

La incorporación de la fórmula Estado social de derecho a la Ley Fundamental de Bonn hace preguntarse a Forsthoff (1986, p. 80) si es posible la unión del elemento social y del liberal en la unidad de una constitución. Se trata de tomar el Estado de Derecho en su sentido más estricto y, sobre la base de su sistema conceptual, contrastar hasta dónde y en qué medida es compatible con los contenidos y exigencias del Estado social.

Para este autor las fórmulas del Estado de Derecho y del Estado social son incompatibles a nivel constitucional, y sólo admite la eficacia de este último en el ámbito de legislación ordinaria y en el marco de actuación de Administración, que es donde el Estado social realiza sus funciones. Además, las garantías del Estado de Derecho no pueden extenderse al aseguramiento de los fines del Estado social, que es un concepto diferente y no susceptible de formulación jurídica. El Estado

\footnotetext{
Fuera de Alemania es conocida la postura de M. S. Giannini (1977, p. 139-165), quien considera el concepto de Estado social ambiguo y propone abandonar dicho término porque es científicamente poco significativo y politológicamente infeliz. Este término, dice el constitucionalista italiano, se refiere sólo a una connotación morfológica de ciertos Estados en los que se constitucionalizaron derechos sociales, es decir, situaciones de derecho subjetivo en orden a instituciones de protección social.
} 
social no es un concepto jurídico y, por lo tanto, no puede generar ni derechos, ni obligaciones.

Para Forsthoff (1986, p.83-84) no caben soluciones de compromiso. La Constitución del Estado de derecho se caracteriza por un alto grado de formalización. De esta manera se disocia de los elementos ideológicos, lo que permite adaptar el Estado de derecho a las condiciones presentes, que son diferentes a las del siglo XIX. Esta formalización se manifiesta en la división de poderes, en el concepto de ley como norma general y abstracta, en el principio de legalidad de la Administración, en la garantía de los derechos fundamentales y en la independencia de los tribunales. Si se dan estos elementos, se da la eficacia del Estado de derecho.

Continúa explicando el autor cómo las garantías de las constituciones democráticas son compatibles con las exigencias del Estado de derecho. Y es así porque la mayor parte de esas garantías consisten en límites que acotan los ámbitos del poder. Las garantías de los derechos fundamentales pueden establecerse de modo general y abstracto. Pero, no así las garantías que vinculan al individuo y al Estado. Las garantías jurídico-sociales confieren derechos de participación. Libertad y participación son nociones cardinales que definen la situación del individuo con relación al Estado.

La libertad se garantiza mediante una limitación. El Estado se autoimpone límites y deja al individuo en su situación social. La participación es un derecho y una pretensión que conlleva un Estado que ayuda, reparte, adjudica y no abandona al individuo en su situación social. Estado de derecho y Estado social son en este sentido diversos, por no decir antagónico (Forsthoff, 1986, p. 85-86).

Según Forsthoff, las normas sociales tienen el problema de su aplicación inmediata. Una Constitución no puede concretar todos los aspectos de la regulación social. Por otro lado, si son normas de carácter genérico precisan de la intervención del legislador y, por lo tanto, no pueden ser aplicadas directamente. Para Forsthoff (Forsthoff, 1986, p. 87-88), las normas constitucionales deben poder aplicarse inmediatamente, de lo contrario se trataría de disposiciones meramente programáticas. Existe una contradicción entre la estructura del Estado de derecho y las obligaciones de índole social. Por tanto, no se pueden introducir en el derecho constitucional material la fórmula del Estado social. Estado social y Estado de derecho se encuentran en una situación de tensión. Un abuso del Estado de derecho acabaría con la función social y pondría en peligro el propio Estado. Un abuso del Estado social llevaría a un Estado de administración terminando con el Estado de derecho (Forsthoff, 1986, p. 106). Sin embargo, a pesar de estas apreciaciones, el autor no niega cierta validez a la fórmula del Estado social de derecho. Según Forsthoff, tiene un carácter teleológico a favor del Estado social. La opción 
constitucional por el Estado social debe interpretarse como una vinculación en cualquier aplicación del derecho por los tribunales y la Administración. Frente a la postura de Forsthoff, la mayoría de la doctrina defiende el carácter jurídicoconstitucional del Estado social y su compatibilidad con el Estado de derecho.

Así, Abendroth (1973, p. 266) considera la fórmula, cuyos componentes son compatibles y complementarios entre sí, como una norma fundamental de Derecho que constituye la base de todo el ordenamiento jurídico y del orden político. Es una precondición lógica para la interpretación de todas las demás normas. Aunque en la Ley Fundamental de Bonn no se establezca en qué consiste exactamente la función social del Estado, sí que se puede establecer materialmente un contenido mínimo de ese principio que vincula toda la actividad estatal. Según Abendroth (1973, p. 280), y citamos textualmente, "la conexión de la idea de Estado social de Derecho con la idea de democracia pone de manifiesto que este Estado tiende a conseguir en cada caso una situación de compromiso entre los grupos sociales que garantice un mínimo de criterios comunes de valor admisible para todos". Concluye diciendo que la intervención del Estado, decidida democráticamente y con el fin de trasformar el orden económico y social, será necesaria en el momento en que se vea amenazada la existencia digna de un grupo.

Hoy en día el carácter programático que se le atribuía al Estado social y su falta de eficacia jurídica son planteamientos ampliamente superados. Como indica Benda, en la actualidad existe un consenso generalizado en torno a su consideración como un principio rector vinculante o como una prescripción de los fines del Estado.

El Estado social ha adquirido una enorme importancia que se ha visto reforzada, en primer lugar, por su unión al Estado de derecho y, en segundo lugar, por su protección gracias a la inclusión en el artículo $79.3^{\circ}$ de la Ley Fundamental de Bonn de la "cláusula de intangibilidad" (Benda, 1996, p. 521 y ss). Ahora bien, como apunta Benda el problema de la fórmula del Estado social de derecho estriba en su carácter abierto, con el consiguiente peligro de que el Derecho constitucional descienda al nivel del debate político cotidiano, lo que puede llevar a degradar el concepto constitucionalizado a la "condición de fórmula vaporosa” (1996, p. 522).

En España, el debate en torno a la eficacia jurídica y a la naturaleza del Estado social y democrático de derecho llega en 1978 cuando el constituyente decide reconocer esta fórmula en el artículo $1.1^{\mathrm{o}} \mathrm{y}$ desarrollarla ampliamente a lo largo del todo el texto ${ }^{6}$. García-Pelayo ha considerado que el artículo $1.1^{\circ} \mathrm{CE}$ pertenece

\footnotetext{
Sobre la proyección de la misma en el articulado de la Constitución, véase al respecto el trabajo de E. Garrorena Morales, El Estado español como Estado social y democrático de Derecho (1987, p. 48 a 87$)$.
} 
a las denominadas normas fundamentales o constitutivas del Estado que definen su principios estructurales y sus funciones. En palabras del propio autor estamos ante una norma de "carácter acuñador, generador, germinal o troncal de otras normas de la Constitución”.

Con relación a la fórmula contenida en este precepto la define, no como una simple yuxtaposición de sus tres componentes "el objetivo social, la concepción ascendente o democrática del poder y el sometimiento de ambos términos al Derecho", sino como una totalidad conceptual. Si se dejara que cada uno de los términos siguiese su propio desarrollo dialéctico, podría conducir, según García-Pelayo, al antagonismo con el resto de elementos. Cada uno de ellos, no sólo está limitado por los otros dos, sino que, además, debe ser interpretado a partir de los mismos en su contenido concreto. En consecuencia, el Estado de derecho permite la protección de los derechos constitucionalizados y, así mismo, adquiere un contenido social y democrático. Por su parte, el Estado democrático, en conexión con el principio social y el Estado de derecho, pone fin a la oposición entre democracia formal y democracia social.

Igualmente, se termina con el antagonismo entre liberalismo y democracia. Las decisiones de la mayoría no están sobre el derecho, sino bajo el derecho y no son, eo ipse, ni justas ni constitucionales, existiendo la posibilidad de controlar su validez ante la jurisdicción constitucional. Por último, señala García-Pelayo (1995, p. 92104), el principio social ha de ser entendido como jurídicamente vinculante, de manera que la satisfacción de la procura existencial ha de entenderse como un derecho de los ciudadanos y una obligación para el Estado. Además, este principio sirve como parámetro interpretativo para comprender el Estado democrático de derecho $^{7}$. Sin embargo, después de casi tres décadas de vigencia de nuestra Constitución, desde sectores importantes de la doctrina se insiste en el progresivo deterioro del Estado social y en la necesidad de buscar soluciones en el marco del derecho constitucional.

Por ejemplo, el profesor De Cabo Martín (2006), frente a la inminente erosión del principio de supremacía y de normatividad de la Constitución y ante el vaciamiento de contenido del Estado social, propone construir, sobre la base del principio constitucional de la solidaridad, un concepto de Estado social interventor y

\footnotetext{
La literatura española sobre esta cuestión es muy extensa. Sin ánimo de ser exhaustivos, además de los trabajos ya citados de A. Garrorena Morales (1987), de E. Díaz (1988) y de J. García Cotarelo (1990), puede consultarse la obra de L. Parejo Alfonso (1983). Así mismo, se ha convertido en una obra de referencia el trabajo del mexicano J. R. Cossio Díaz (1989, p. 25 a 42 y 121 a 171) "en estas últimas se estudia la principal jurisprudencia del Tribunal Constitucional sobre el artículo $1.1^{\circ}$ CE“. También es interesante el libro escrito por C. Carmona Cuenca (2000). Por último, para una aproximación al tema puede leerse la aportación de J.L. Cascajo Castro (1992, p. 9 y sigs).
} 
transformador. De Cabo Martín considera el Estado social y democrático de derecho como una estructura dentro de la cual el Estado social es el condicionante básico del Estado democrático y del Estado de derecho ${ }^{8}$. El principio del Estado social determina la configuración del resto de bienes protegidos por la Constitución y provoca la transformación del derecho. El derecho no solo asume una función promocional, sino que amplía sus competencias casi de manera ilimitada, provocando una juridificación de la sociedad o una "lluvia de normas" 9 . Pero, la transformación del derecho no es solo cuantitativa, sino también cualitativa en el sentido del predominio del aspecto objetivo del derecho sobre el subjetivo. La objetivación del derecho, concluye De Cabo Martín, es un reflejo del carácter pactado de las normas y de la revalorización que ha de tener el pluralismo en el proceso legislativo.

Sin negar, en ningún momento, la crisis económica que ha hecho sacudir los cimientos del Estado social, siendo utilizada por muchos para poner en entredicho incluso su propia existencia, no podemos compartir el pesimismo doctrinal del profesor De Cabo (2006, p.16), según el cual, a pesar del reconocimiento que se hace en el texto constitucional, en la realidad socio-política el Estado social se encuentra fuertemente transformado o en vías de extinción. Al menos no es así en el ámbito del derecho a la protección de la salud. Si bien es cierto que las exigencias establecidas en el artículo $43 \mathrm{CE}$, en conexión con los artículos $1.1^{\circ} \mathrm{CE}$ y $9.2^{\circ}$ $\mathrm{CE}$, se han cumplido a través de la legislación ordinaria y de la actuación de la Administración sanitaria, tanto estatal como autonómica, la normatividad y la supremacía constitucional han estado siempre presentes desde que se aprobó la primera Ley General de Sanidad en el año 1986. Y ello a pesar de las dificultades añadidas en el marco de un Estado política y jurídicamente descentralizado.

No obstante, sí compartimos con De Cabo (2006, p.17) la necesidad de recuperar la riqueza y complejidad teórica del Estado social, que en la práctica va más allá de la mera prestación de servicios, y cuya esencia está en la intervención y en la transformación de la sociedad a través del derecho. Y todo ello en el marco de un derecho constitucional combativo ${ }^{10}$.

\section{Los derechos sociales como derechos fundamentales}

\subsection{Derechos sociales y Constitución}

8 Este carácter condicionante se comprueba empíricamente porque como consecuencia de la crisis económica se produce la del Estado social y a su vez la crisis del Estado social afecta a los postulados del Estado democrático y del Estado de derecho, reduciéndose la democracia política y social y las garantías en sectores relevantes (De Cabo, 2006, p. 50).

9 La expresión y entrecomillado son del propio De Cabo (2006, p. 21).

10 La idea de un Derecho constitucional garantista y beligerante frente a la "mitezza" o ductilidad propuesta por Zagrebelsky, la ha defendido De Cabo Martín en varias ocasiones (1994, p. 35 y sigs.). 
Los derechos sociales representan una de las categorías más problemáticas del derecho constitucional, ya que no es fácil, a partir del tenor literal de las Constituciones contemporáneas, establecer cuál es su fundamento, su naturaleza y su eficacia jurídica, ni tampoco el nexo que existe con los clásicos derechos de libertad.

En efecto, en torno a los derechos sociales se ha discutido durante décadas y, a pesar de ello, resulta un debate inconcluso, sin resultados teóricos aparentemente demasiado satisfactorios. Este hecho ha llevado a algunos autores a hablar incluso en términos de aporías ${ }^{11}$. Sin embargo, tal y como reclama Gomes Canotilho (1998, p. 35-36), frente a esta especie de capitulación-resignación, sobre todo de su régimen de garantías, los derechos económicos, sociales y culturales han de regresar al espacio jurídico constitucional y ser considerados como elementos esenciales de una comunidad jurídica bien ordenada.

Desde su aparición los derechos sociales se han considerado por la doctrina constitucional incomprensibles en su esencia jurídica y no asimilable a la categoría de los derechos fundamentales en sentido estricto ${ }^{12}$. Los derechos sociales han sido algo ajeno a la lógica de los sistemas jurídicos del Estado de derecho liberal. Su tardía constitucionalización, llevada a cabo tras la II Guerra Mundial, ha dificultado notablemente su comprensión. Además, las Constituciones han sido muy ambiguas a la hora de reconocerlos, siendo necesaria la intervención de la jurisprudencia para dotarlos de un estatuto conceptual adecuado que los sacara del limbo del pregiuridico ${ }^{13}$.

Desde una perspectiva histórica, la relación entre derechos sociales y Constitución ha pasado por cuatro fases que Barbara Pezzini (2001, p. 45-94) delimita de la siguiente manera. La fase inicial -denominada por la autora fase reduccionista o de exclusión- coincide con el nacimiento y desarrollo del constitucionalismo moderno y se extiende a lo largo de todo el siglo XIX. Este período se caracteriza por un rechazo a la inserción de los derechos sociales en las Constituciones: puesto que el Estado no tienen poder para disponer sobre los bienes o las prestaciones que deberían ser garantizadas por los derechos fundamentales de naturaleza social, y en consecuencia se niega su juridicidad. La segunda fase -fase orgánica- se sitúa en los años de la primera postguerra mundial. Algunas disposiciones de carácter social se incluyen en las Constituciones bajo la forma de obligaciones para el Estado, que debe desarrollar determinadas funciones sociales, ya que existe un interés público que se inserta orgánicamente en la Constitución. Ahora bien, estas funciones

1 Cfr. al respecto los trabajos de R. García Macho (1992, p. 102) y Cascajo Castro, (1988, p. 29 a 34).

12 Explica Baldassarre (1997, p. 1), que "[...]ipotizzare una prestazione sociale come oggetto o contenuto di un diritto soggettivo e, nello stesso tempo, configurare una pretesa o un potere dispositivo nei confronti del sovrano (legislatore) contraddicevano i principi di fondo su cui si poggiava l'intera impalcatura giuridica".

13 La expresión es del propio A. Baldassarre. 
atribuidas a los poderes públicos no conllevan el reconocimiento de derechos para los ciudadanos, aunque en los propios textos se utilice la expresión "derecho" ¿Cómo se resuelve esta situación, esta fonte di ambiguità? Bien relativizando el contenido del término "derecho", o bien forzando el alcance de la categoría de los derechos sociales hasta llegar a asimilarlos con otros derechos constitucionalmente garantizados. En la tercera fase -fase solidaria o de igualdad sustancial-, que se inicia al final de la II Guerra Mundial, los textos constitucionales incorporan el principio personalista, que modifica sustancialmente el objetivo de las funciones del Estado. Ya no se trata de proteger sólo el interés público, sino que la intervención estatal se centra en la protección del interés individual.

Además, la introducción del control de constitucionalidad y de sus instrumentos de garantía permite reconstruir una unidad jurídica normativa que deja apreciar todos los aspectos subjetivos de los derechos sociales. Por último, en el momento actual -fase identitaria y relacional- nos encontramos con una revalorización del carácter individual de los derechos sociales que coexiste con una reducción de la voluntad y de la capacidad política para resolver problemas complejos de tutela social. Un declive del intervencionismo, íntimamente relacionado con lo que se viene denominado crisis del Estado del bienestar.

También Baldassarre (1997, p. 2 y sig.) realiza un análisis histórico sobre la aparición y desarrollo de esta nueva categoría del derecho constitucional. Durante la experiencia de Weimar las normas constitucionales que contenían derechos sociales fueron consideradas por un amplio sector de la doctrina como proposiciones sin un significado específico; premisas, indicaciones que sólo el legislador podía transformar en preceptos normativos, de tal manera que los derechos sociales se convertirían en verdaderos derechos tan sólo en la medida que así se estableciera en una ley. Para otros, los denominados derechos sociales eran normas de principio, vinculantes para el legislador ordinario que está obligado a desarrollarlas. Para ambas concepciones, señala Baldassarre, los derechos tienen un valor político, pero no jurídico, ya que no disponen de una tutela inmediata, ni son accionables directamente. Necesitan la intervención del legislador, que goza de un amplio margen de discrecionalidad, para transformase en auténticas pretensiones jurídicas.

Esta oposición entre los derechos clásicos de libertad y los nuevos derechos sociales se mantuvo incluso después de la entrada en vigor de las Constituciones de la segunda postguerra. Pero, en este momento histórico las diferencias entre ambas categorías se fundamentaban sobre la base del antagonismo existente entre los principios del Estado de Derecho liberal (la libertad en sentido negativo) y los principios del Estado social democrático (la igualdad material). Esta tensión se podría superar, según los teóricos de la época, si se considerasen los derechos sociales como meros principios programáticos, ya que sólo los derechos de libertad 
son derechos originarios. Por el contrario, los derechos sociales, según su naturaleza y su propia ratio son "derechos de status", "derechos de participación" concedidos por el Estado. Los derechos de libertad son derechos constitucionales, mientras que los derechos sociales son tan sólo derechos de configuración legal, cuya exigibilidad depende única y exclusivamente de la intervención del legislador ordinario (Baldasarre, 1997, p. 4 y 5).

Estos planteamientos ponen de manifiesto la incapacidad para superar los límites tradicionales del Estado de derecho liberal y para formular una reinterpretación del mismo acorde con los cambios producidos a partir del establecimiento de los nuevos sistemas de democracia pluralista. Efectivamente, el triunfo de la democracia impuso una revisión de los fundamentos del Estado de derecho liberal y la necesaria conciliación entre los principios de libertad e igualdad. Ni la libertad abstracta, ni la igualdad formal aseguran que todos los individuos puedan gozar de los derechos fundamentales, ni que las necesidades sociales puedan ser satisfechas de igual manera (Luciani, 1980, p. 771 y sig.).

Durante años se ha recurrido a la figura de los diritti civici para definir los derechos sociales como derechos legales. Según Baldassarre, este recurso es inadecuado. ¿Por qué? Recuerda el autor que los diritti civici tenían sentido en aquellos ordenamientos jurídicos en los que los derechos de los ciudadanos se basaban en una ley ordinaria o en una constitución flexible. Sin embargo, desde el momento que los derechos de los ciudadanos, incluidos los sociales, son reconocidos y garantizados por una constitución rígida ya no se puede defender su carácter legal. Tampoco es sostenible, prosigue el autor, la contraposición derechos sociales versus derechos de libertad, basada en la idea de que los derechos sociales requieren prestaciones positivas, mientras que los derechos de libertad comportan sólo un deber de respeto y de abstención.

En la misma línea señala Mazziotti (1964,p. 804 y sig.) que hay derechos sociales cuyo ejercicio no precisa de la intervención del legislador y derechos de libertad que sí la requieren para su efectividad y para dotarlos de una garantía concreta. Mazziotti define el derecho social, en sentido objetivo, como el conjunto de normas mediante las cuales el Estado lleva a cabo su función moderadora de las diferencias sociales, con el fin de asegurar la igualdad. Desde una perspectiva subjetiva, se define como el derecho de cada individuo a participar en los beneficios de la vida asociada, que se manifiesta en derechos concretos a determinadas prestaciones de los poderes públicos ${ }^{14}$. Los derechos de libertad implican la existencia de una esfera

14 Esta definición excluye de la categoría de los derechos sociales a todos aquellos derechos públicos subjetivos que consisten en el ejercicio de una libertad, como por ejemplo el derecho de asociación sindical o el derecho de huelga Mazziotti (1964, p. 804). 
dentro de la cual el individuo puede actuar libremente; los derechos sociales buscan la intervención del poder público para satisfacer necesidades básicas de los ciudadanos; los derechos de libertad civiles reflejan el denominado status negativus sive libertatis, los derechos de libertad políticos el status civitatis activae y los derechos sociales el status socialis positivus. Aunque éstos se fundamenten en el principio de igualdad, las diferencias entre ambas categorías no deben entenderse como un antagonismo. Al contrario, entre ambas existe una implicación recíproca. Según se expresa Mazziotti “[...]la garanzia dei diritti di libertà è condizione perché le prestazioni sociali dello Stato possano essere oggetto di diritti individuali; la garanzia dei diritti sociali è condizione per il buon funzionamento della democrazia, quindi per un effettivo godimento delle libertà civili e politiche”. Mazziotti (1964, p. 805).

Afirma Luciani (1991, p. 3, 4; 1994, p. 99 y sig.) que entre los derechos sociales y los derechos clásicos de libertad existe una discontinuidad histórica, pero, no ontológica ni tampoco lógica. La pretendida a-socialità de los derechos de libertad no es admisible, porque ninguno de los derechos fundamentales clásicos tiene sentido sin una dimensión social. Ningún derecho fundamental es tal si no cuenta con una intervención social que haya institucionalizado su protección. No se puede perder de vista, dice el autor, que la principal garantía de los derechos de libertad es su consideración como un derecho de prestación, al igual que la mayor parte de los derechos sociales. En definitiva, concluye el autor, cuando utilizamos la expresión derechos sociales nos estamos refiriendo a una clase de derechos que se distingue del resto de derechos constitucionalizados sólo por su origen histórico y por su peculiar relación con el principio de igualdad material del artículo 3.2 de la Constitución italiana.

La prioridad histórica de los derechos de libertad los convierte en un prius lógico con relación al resto de los derechos inviolables y condicionarían la existencia misma de la democracia, mientras que los derechos sociales vendrían sólo a caracterizar, eso sí, de manera determinante, el significado de la Constitución. Esta afirmación se fundamenta, según Luciani, en dos premisas: primera, que los derechos de libertad son categorie a priori de la democracia pluralista y, segunda, que estos derechos son "[...]le "strutture di base" della persona, destinate a rappresentare il supporto (categoriale) su cui "lógicamente" si appoggiano tutte le altre forme di estrinsecazone della personalità umnana" (Luciani, 1991, p. 3). Luciani admite la primera de las premisas. Sin embargo, no comparte la segunda, porque, si se utiliza un concepto de persona en su dimensión social, entonces también los derechos sociales formarían parte de su estructura básica.

En general, la mayor parte de la doctrina italiana sigue recurriendo a definiciones unitarias de los derechos sociales como derechos del ciudadano a una prestación 
positiva por parte del Estado, en contraposición a los derechos de libertad que imponen a los poderes públicos un deber de abstención, respetando la esfera privada del individuo.

Sin embargo, hay autores que, como Corso (1981, p. 759 y sig.), subrayan el hecho de que bajo el término derechos sociales en la Constitución se engloben "in modo riassuntivo pretese giuridiche verso i pubblici poteri, interessi legittimi, diritti di credito nei rapporti interprivati, forme di controllo sull'esercizio di poteri pubblici, fini pubblici non coordinati a pretese giuridiche dei soggetti privati, meccanismi di garanzia”.

Baldassarre $(1989$, p. 30 y sig.) también se muestra crítico con la tendencia que unifica bajo la denominación derecho social una rica pluralidad de situaciones jurídicas. Primeramente, porque entra en contradicción con una concepción de los derechos sociales como derechos constitucionales; en segundo lugar, porque no es capaz de captar la verdadera diferencia entre derechos de libertad y derechos sociales $\mathrm{y}$, por último, porque no recoge la variedad de situaciones que se engloban bajo esta categoría. Dentro de la categoría genérica de los derechos sociales distingue dos subgrupos: los derechos sociales de libertad y los derechos sociales a prestaciones. Es indiscutible que los derechos de libertad, una vez constitucionalizados, son aplicables directamente. Esto se debe, no ya a su valor o a la garantía que los ampara, sino a su estructura jurídica: su ejercicio depende únicamente del comportamiento o de la conducta de su titular. Ahora bien, la "autoaplicabilidad", así denominada por Baldasarre, también es propia de algunos derechos sociales, los llamados derechos sociales de libertad, entre los que se incluyen la libertad de elección de profesión (artículo $4 \mathrm{CI}$ ), la libertad de enseñanza (artículo $33 \mathrm{CI}$ ), la libertad sindical (artículo $39 \mathrm{CI}$ ), etc. Este autor propone incorporar también a este grupo el derecho a la salud (artículo $32 \mathrm{CI}$ ), que en opinión de la jurisprudencia de la Corte Costituzionale tiene las mismas características que los derechos de libertad. Su estructura jurídica es del todo semejante a la libertad personal (artículo $13 \mathrm{CI}$ ). La libertad personal protege al individuo en su integridad física y psíquica frente a amenazas o lesiones, directas y actuales. El derecho a la salud protege a la persona de agentes de morbilidad o de actividades lesivas de terceros que afectan al entorno personal o colectivo y que, posteriormente, tienen repercusiones sobre las personas.

Según este autor la expresión derecho social no parece la más adecuada para denominar la riqueza de situaciones que aparecen recogidas en el Título II y II de la Parte I de la Constitución italiana. Para distinguir lo que son derechos sociales de otras situaciones jurídicas, Corso propone tres criterios: la titularidad, el sujeto pasivo obligado con relación al sujeto titular y los medios de tutela. En cuanto a la titularidad: el derecho social no es un derecho de todos. La atribución de un derecho social se hace en 
función de una situación de desigualdad, de exclusión, de discriminación. Es un derecho individual, pero la pertenencia a un grupo identifica al sujeto titular del mismo. No obstante, el autor es consciente de que este criterio no es absoluto porque la tendencia generalizada es hacia la universalización de la titularidad. Piénsese, sin ir más lejos, en el derecho a la protección de la salud: de ser un derecho reservado a la clase trabajadora ha pasado a ser un derecho de todos los ciudadanos. El segundo criterio es el del sujeto pasivo obligado. En este punto Corso señala la variedad de sujetos obligados que existen: el legislador, la Administración pública, los individuos particulares. Hay incluso supuestos, como en el caso del derecho a la salud, entendido como derecho a la integridad física, o del derecho a la protección del medio ambiente en los que los sujetos pasivos pueden ser varios. Finalmente, Corso se detiene en la observación de los distintos mecanismos de tutela: el control de constitucionalidad, la tutela judicial ordinaria, la tutela contencioso- administrativa, la tutela penal y la tutela de la Administración pública.

El segundo grupo de derechos está integrado por los que él denomina derechos sociales a prestaciones, cuyo contenido consiste en una pretensión jurídica frente a otros sujetos con el fin de que éstos adopten determinados comportamientos o conductas a favor del titular del derecho. Insiste Baldassarre en que estos últimos no se pueden confundir con las normas programáticas ${ }^{15}$. ¿Cuál es la diferencia entre ambas categorías? Si bien en ambos casos el legislador dispone de un margen de discrecionalidad para establecer sobre cómo y cuándo desarrollarlos, sin embargo, no tiene capacidad para decidir el si y el quid de la garantía del derecho. Si así fuera, se estaría degradando el derecho social constitucionalizado a un derecho legal.

Dentro de los derechos sociales a prestaciones, Baldassarre distingue dos categorías: los derechos sociales incondicionados y los derechos sociales condicionados. Los derechos sociales incondicionados se refieren a prestaciones que pueden ser exigidas directamente por sus titulares al sujeto obligado (público o privado). Entre estos derechos Baldassare incluye el derecho a recibir cuidados médicos, el derecho de las mujeres a la igualdad en las condiciones de trabajo, el derecho al descanso y a vacaciones, etc. En caso de conflicto, corresponde al juez determinar el quatum de la prestación, a no ser que éste se prevea en la ley. Los derechos sociales condicionados, por el contrario, dependen para su ejercicio de la existencia de una organización que dispense las prestaciones, como sería el caso del derecho a las prestaciones sanitarias o el derecho de los indigentes a los cuidados gratuitos.

\footnotetext{
15 Una norma programática en la que aparece, por ejemplo, en el artículo $31 \mathrm{Cl}$ "La Repubblica protegge la maternità, l'infanzia e la gioventù". Un derecho social a prestaciones es el contemplado en el artículo $38 \mathrm{Cl}$ "Ogni cittadino inabile [...] ha il diritto al mantenimento e all'assistenza". (Baldassarre, 1989, p. 30).
} 
Cuando se dan las condiciones de hecho para el disfrute de estos derechos, no cabe duda de que dan lugar a pretensiones jurídicas que se pueden ejercer directamente y proteger mediante la vía judicial. Pero, ¿qué ocurre si no se da el supuesto de hecho, si no existen las instituciones proveedoras de estas prestaciones? Baldassarre señala, acertadamente, que en este caso no se vería afectada la garantía del derecho social. Esta protección, establecida por la Constitución, no puede negarse porque significaría negar el carácter constitucional de estos derechos ${ }^{16}$.

El mayor error de la doctrina a la hora de interpretar la joven categoría de los derechos sociales ha sido, según Baldassarre (1989, p. 29), el siguiente: se han confundido los problemas ligados a la aplicabilidad y a la garantía de los derechos sociales con cuestiones relacionadas con su naturaleza jurídica: "[...]la trasposizione dei problemi di "fattibilità" o di attuazione in problemi di natura concettuale od "ontologica", se non proprio di valore, è senza dubbio alcuno una scorrettezza logica, poiché tra i due ordini di questioni non c'è ponte".

Para Baldassarre, los derechos constitucionales son, ante todo, valores, entre los que existe una unidad y un equilibrio, que en determinados momentos precisan la protección del Estado y en otros su intervención en forma de prestaciones. Los derechos sociales no son una categoría meramente descriptiva. Están ligados a un status social.

Son, además principios constitucionales orientados a la redistribución de los recursos económicos, sociales y políticos. En definitiva, los derechos sociales son "la testimonianza concreta della socialità dello Stato democratico voluto dalla Costituzione e della sintesi di valore che la sorregge continuamente, quella tra la libertà individuale e l'eguaglianza". Los derechos sociales tienen el estatuto típico de los derechos fundamentales. Desde el punto de vista de su valor jurídico, son

$\overline{16}$ En este punto Baldassarre se detiene en el análisis de la fórmula alemana de la reserva de lo posible o de lo razonable. En materia de derechos sociales hay que distinguir entre el reconocimiento que hace la Constitución y su garantía concreta, limitada por la reserva de lo posible. Este principio no significa que el legislador disponga de una total discrecionalidad para desarrollar los derechos. Por el contrario, está obligado a graduar su ejercicio, de acuerdo con el marco general de los intereses constitucionalmente reconocidos y de conformidad a las exigencias de los presupuestos del Estado. BALDASSARRE valora positivamente el recurso a esta fórmula, si bien recuerda que en Italia, a diferencia de lo que ocurre en Alemania, los derechos sociales están no sólo reconocidos, sino también garantizados por la Constitución de 1948, de manera que la Corte Costituzionale puede controlar la actividad del legislador y verificar si se ha utilizado la debida ragionevolezza a la hora de desarrollar los derechos sociales. La utilidad de esta fórmula la resume el autor que venimos comentando en tres puntos. En primer lugar, permite identificar cuál es el verdadero problema de los derechos sociales condicionados: no se trata de su naturaleza jurídica sino de establecer una graduación en el momento de ser desarrollados por el legislador. En segundo lugar el principio de la reserva de lo posible permite a la Corte Costituzionale valorar la ragionevolezza del legislador en su tarea de regular el ejercicio de los derechos sociales. Por último, posibilita a la Corte para enjuiciar si el legislador ha respetado la ratio de cada derecho. 
irrenunciables, inalienables, indisponibles, intransmisibles e inviolables. Desde el punto de vista de su eficacia, la Corte Costituzionale ha establecido que todos los derechos sociales que han sido desarrollados por el legislador ordinario tienen la misma eficacia que los derechos de libertad (Baldassarre, 1989, p. 31).

No comparte esta opinión Alessandro Pace (1998, p.20 y sig.), para quien el reconocimiento constitucional de un derecho tiene como única consecuencia que el legislador no pueda vulnerarlo. Sin embargo, lo que él denomina "cobertura constitucional" no dice nada respecto a su indisponibilidad, intransmisibilidad, irrenunciabilidad e imprescriptibilidad. Estas características se derivan, prosigue diciendo el autor, no de su reconocimiento constitucional, sino de su calificación como "derecho de la persona".

Así mismo, la mayor o menor tutela jurisdiccional que pueda obtener un derecho constitucional depende de su estructura de derecho absoluto o bien de derecho relativo, en el sentido de derechos oponibles erga omnes y derechos oponibles sólo en las relaciones con determinados sujetos ${ }^{17}$.Los derechos absolutos comprenden los derechos de la persona y los derechos reales. Desde el punto de vista de su estructura, ambas categorías de derechos no necesitan la intervención de un tercero para realizar el interés que incorporan. Entre los derechos de la persona, hay un grupo de derechos que consisten en el ejercicio de una libertad (agere licere), como puede ser la libertad personal, la libertad de comunicación, etc., o derechos en los que no hay actividad por parte del titular, sino que consisten en bienes o atributos esenciales de la persona, como el derecho a la vida, la integridad física y psíquica, el derecho al nombre, etc. Entre los derechos relativos, consistentes en una obligación, PACE distingue entre los supuestos en los que el derecho se ejerce frente al Estado y los supuestos en los que el sujeto pasivo de la relación es otro particular. Así mismo, dentro de estos derechos relativos, se ha de determinar si el contenido consiste en una prestación positiva, en una omisión o en el ejercicio de un poder. Entre los derechos a una prestación positiva por parte del Estado se encuentran los derechos sociales. Estos están siempre condicionados a la intervención del legislador y de la Administración. Gozan de una tutela mucho más débil, ya sea desde el punto de vista legislativo, ya sea desde el punto de vista judicial que la prevista para los derechos que se han denominado absolutos.

\subsection{Los derechos sociales, ¿son derechos fundamentales?}

Para responder a este interrogante es necesario, en primer lugar, formular una definición de lo que se entiende por derechos fundamentales. Los derechos

$\overline{17} \quad$ Aclara Pace (1998, p. 21) que esta distinción no se hace en el sentido de derechos ilimitados (absolutos) y derechos limitados (relativos). 
fundamentales, además de ser derechos públicos subjetivos, constituyen un conjunto de normas objetivas de principio y de decisiones axiológicas que se recogen en las Constituciones y que tienen validez en todo el ordenamiento jurídico. En esta aproximación al concepto de derecho fundamental confluyen dos dimensiones, una subjetiva y otra objetiva, que han sido formuladas por la doctrina alemana bajo la denominada teoría de la doble vertiente de los derechos fundamentales.

Tras los atroces crímenes cometidos durante los oscuros años del Tercer Reich se produce en Alemania una reacción garantista que reclama una mayor intervención del Estado en la protección y en la configuración de los derechos fundamentales (Hesse, 1996, p. 86). Esta tendencia se refleja, en primer lugar, en los nuevos textos constitucionales aprobados tras la Segunda Guerra Mundial. Entre ellos, la Ley Fundamental de Bonn de 1949 que supera las deficiencias de la Constitución de Weimar de 1919 al introducir mecanismos de tutela, como la intangibilidad de la dignidad humana y la obligación de respetarla y protegerla como tarea del poder del Estado (artículo 1.1 ${ }^{\circ} \mathrm{LF}$ ), la inviolabilidad de los derechos fundamentales (artículo $1.2^{\circ} \mathrm{LF}$ ) y su eficacia directa (artículo $1.3^{\circ} \mathrm{LF}$ ), el establecimiento de límites a sus modificaciones y el respeto de su contenido esencial (artículo 19.2 ${ }^{\circ}$ LF), su protección judicial (artículo $19.4^{\circ} \mathrm{LF}$ ), el control de constitucionalidad de las leyes (artículo 93.1 ${ }^{\circ} .2^{\text {a }}$ LF) y las dos modalidades de recurso de amparo: el recurso de amparo que toda persona puede interponer cuando se considere lesionada por el poder público en uno de sus derechos fundamentales o en uno de sus derechos contenidos en los artículos 20, apartado $4^{\circ}, 33,38,101,103$ y 104, tal y como se establece en el artículo $93.1^{\mathrm{o}} .4^{\mathrm{a}}$, a) LF y el denominado recurso de amparo municipal (artículo $\left.93.1^{\circ} .4^{\mathrm{a}}, b\right)$ ) LF que pueden interponer los municipios y las mancomunidades de municipios por violación a través de una ley, del derecho de autonomía municipal establecido en el artículo 28 LF, exceptuándose, sin embargo, aquellos casos de violación por leyes de los Länder en los que quepa recurso ante la Corte Constitucional.

El fortalecimiento de los instrumentos constitucionales de protección genera, en segundo lugar, el desarrollo de la doctrina y la jurisprudencia alemanas, cuyas aportaciones han supuesto un hito en la reciente historia del derecho constitucional (Böckenförde, 1993, p. 44-71). Entre los mayores logros en la exégesis de los derechos fundamentales hay que destacar, sin lugar a dudas, la teoría de la doble vertiente. Los derechos fundamentales como derechos públicos subjetivos van a experimentar un fuerte desarrollo bajo la vigencia de la Ley Fundamental de Bonn (Böckenförde, 1993, p. 101 y sig.).

Los derechos subjetivos de los ciudadanos están garantizados por la nueva Constitución y su vigencia se extiende a todas las relaciones entre los particulares y el poder del Estado en todas sus dimensiones. Pero, el ejercicio de los derechos 
fundamentales no es ilimitado. Surge el problema de cómo establecer límites a los derechos públicos subjetivos sin vulnerarlos. En torno a esta cuestión se elaboran por la doctrina y jurisprudencia constitucional alemana diversos mecanismos, como el principio de proporcionalidad, la teoría de la interacción o la teoría de los límites inmanentes, que buscan la constitucionalidad de la intervención del legislador en la regulación y desarrollo de los derechos fundamentales.

Como hemos dicho, a la vertiente subjetiva se suma el nuevo carácter objetivo que se predica del conjunto y de cada uno de los derechos fundamentales. Considerados en su totalidad, constituyen un orden objetivo, un sistema de valores que demanda su aplicación en todo el ordenamiento e impone un parámetro de conducta en el seno de la comunidad jurídica. Considerados individualmente, cada derecho es un principio que se une al contenido subjetivo para configurar el derecho fundamental ${ }^{18}$.

Del reconocimiento de la vertiente objetiva se derivan una serie de consecuencias de índole jurídica ${ }^{19}$. En primer lugar, cuando se afirma que los derechos fundamentales son normas objetivas de principio, significa que todos los ámbitos del derecho quedan conformados constitucionalmente, implicando a los tres poderes del Estado en la interpretación y aplicación del ordenamiento jurídico. Este es el denominado efecto de irradiación de los derechos fundamentales. Por otro lado, como valores individuales están protegidos, no sólo frente a los poderes públicos, sino también ante posibles vulneraciones originadas por sujetos privados. En este caso se trata de la denominada eficacia frente a terceros. Por último, como normas

$\overline{18}$ El reconocimiento del carácter objetivo de los derechos fundamentales se plasma por primera vez en la jurisprudencia del Tribunal Constitucional Federal en 1958 el conocido caso Lüth. Según expone $\mathrm{E}$. Böckenförde la aparición de la dimensión objetiva de los derechos fundamentales está relacionada con la búsqueda, ante el fracaso del positivismo jurídico, de un nuevo fundamento del Derecho de la República Federal y del significado de los derechos fundamentales, basado en conceptos axiológicos. Sobre este argumento cfr. E. Böckenförde, "Sobre la situación...", op. cit., págs 104 a 116. Véase también K. Hesse "Significado...", op. cit., págs. 91 a 94. La concepción de los derechos fundamentales como valores arranca de la teoría de la integración formulada por R. Smend en 1928 (Verfassung und Verfassungsrecht). Nos remitimos aquí a la traducción hecha por José María Beneyto Pérez, Constitución y Derecho Constitucional, Centro de Estudios Constitucionales, Madrid, 1985.

19 Sobre los efectos del reconocimiento del carácter objetivo de los derechos fundamentales cfr. E. Böckenförde (1993, p. 109 a 116). Véase igualmente la aportación de K. Hesse (1996, p. 93 y 94$).$ El Estado como ser social, está sujeto a un continuo proceso de actualización funcional, de reproducción, de laboriosa configuración social. El Estado no es una totalidad inmóvil, sino que está sometido a un permanente proceso de integración. Para R. Smend "el fundamento de la legitimidad [del Estado] son los valores concretos que actúan, por un lado, como factores y, por otro, como elementos básicos de la validez de un orden jurídico-político determinado" (p. 101). Los derechos fundamentales son factores constitutivos de este proceso. A través de ellos se establece un sistema de valores. Los derechos fundamentales son normas objetivas que reciben el contenido objetivo del fundamento axiológico de la comunidad estatal. Sobre la teoría axiológica de R. Smend y su influencia en la elaboración de la teoría de la doble vertiente de los derechos fundamentales, véase J.L. Cascajo Castro, (1979, p. 275), y también Böckenförde, "Teoría e interpretación (1993, p. 57 a 60) y "Sobre la situación...", (1993, p. 105). 
de principio o decisiones axiológicas poseen un contenido normativo que requiere ser desarrollado. No son derechos que persigan la abstención, sino que pretenden la actuación y protección de sus contenidos. Los derechos fundamentales constituyen, pues, mandatos de acción y deberes de protección.

Entre ambas vertientes, subjetiva y objetiva, no existe una simple yuxtaposición, sino, como indica Hesse, una relación de remisión y complemento recíprocos (Hesse, 1996, p. 91 ${ }^{20}$. En España, la teoría de la doble vertiente de los derechos fundamentales ha quedado reflejada en el propio texto constitucional. En efecto, la Constitución de 1978, en su artículo $1.1^{\circ}$, propugna como valores superiores del ordenamiento jurídico la libertad y la igualdad y declara, en su artículo $10.1^{\circ}$, como fundamento del orden político y de la paz social, la dignidad de la persona y los derechos inviolables que le son inherentes. Así mismo, nuestra Norma Fundamental recoge los efectos derivados del reconocimiento de la vertiente objetiva de los derechos fundamentales: el efecto de irradiación (artículo $1.1^{\circ}$ y $10.1^{\circ} \mathrm{CE}$ ), su eficacia directa, frente a los poderes públicos y a los ciudadanos (artículo $9.1^{\circ} \mathrm{CE}$ ) y su configuración como mandatos de actuación y protección (artículo $9.2^{\circ} \mathrm{CE}$ ).

Como explica Pérez Luño (1984, p. 20 y sig.), los derechos fundamentales en la normativa constitucional se presentan como un conjunto de valores objetivos básicos y, al mismo tiempo, como el marco de protección de las situaciones subjetivas, desempeñando una doble función. En el plano subjetivo, son garantías de la libertad individual y de aquellos aspectos que contribuyan al pleno desarrollo de la subjetividad humana. En el plano objetivo, aseguran la consecución de los fines y los valores constitucionalmente proclamados.

Para el profesor Pérez Luño el significado axiológico de los derechos fundamentales es el fruto de un acuerdo entre las distintas fuerzas sociales. En este sentido, los derechos fundamentales constituyen el conjunto de valores esenciales de cada sociedad. Sistematizan el contenido axiológico-objetivo del ordenamiento democrático y garantizan un proceso político libre y abierto. Además de ser límites al ejercicio del poder, son fines directivos de la acción positiva de los poderes públicos. El aspecto objetivo se suma a la dimensión subjetiva de los derechos fundamentales en la que se establece el estatuto jurídico de los ciudadanos en sus relaciones con el Estado y con otros individuos. Así mismo, el contenido subjetivo de los derechos fundamentales va a experimentar un importante desarrollo: además

\footnotetext{
20 Aunque haya discrepancias en cuanto a la relación entre el aspecto subjetivo y objetivo de los derechos fundamentales -véase el epígrafe dedicado por E. Böckenförde al estudio de la conexión entre los dos aspectos en "Sobre la situación...", (1993, p. 117 a 125)-, prevalece la idea de que existe una imbricación entre ambas vertientes. En el mismo sentido se pronuncia P. Häberle, (2003, p. 97 a 115), para quien, como tendremos ocasión de ver más adelante, la relación es de paridad y reciprocidad.
} 
Derecho y Realidad

de extender su ámbito de eficacia frente a terceros particulares, su contenido material se amplia. En este sentido Pérez Luño afirma lo siguiente: en la medida en que se toma conciencia de que el disfrute de los derechos y libertades exige una serie de condiciones materiales, surge el status positivus socialis que incluye los denominados derechos económicos, sociales y culturales. Estos derechos garantizan el pleno desarrollo de la subjetividad humana y, por tanto, pasan a integrar la categoría de los derechos fundamentales.

También la jurisprudencia del Tribunal Constitucional ha hecho suya la teoría de la doble vertiente al afirmar que los derechos fundamentales constituyen la base misma del orden político-jurídico del Estado en su conjunto:

"Ello resulta lógicamente del doble carácter que tienen los derechos fundamentales. En primer lugar, los derechos fundamentales son derechos subjetivos, derechos de los individuos no sólo en cuantos derechos de los ciudadanos en el sentido estricto, sino en cuanto garantizan un "status" jurídico o la libertad en un ámbito de la existencia. Pero al propio tiempo, son elementos esenciales de un ordenamiento objetivo de la comunidad nacional, en cuanto ésta se configura como marco de una convivencia humana justa y pacífica, plasmada históricamente en el Estado de derecho y, más tarde, en el Estado social de derecho o el Estado social y democrático de derecho, según la fórmula de nuestra Constitución (artículo 11). Esta doble naturaleza de los derechos fundamentales, desarrollada por la doctrina, se recoge en el artículo 10.1 de la Constitución, a tenor del cual "la dignidad de la persona, los derechos inviolables que les son inherentes, el libre desarrollo de la personalidad, el respeto a la Ley y a los derechos de los demás son fundamento del orden político y de la paz social" (STC 25/1981, de 14 de julio, F.J. $5^{\circ}$ ).

Este planteamiento ha sido mantenido hasta la fecha tanto por la doctrina como por la jurisprudencia constitucional española. La teoría de la doble vertiente se ha consolidado, por lo tanto, en nuestro sistema constitucional. Con relación a la aplicación de la citada teoría a la genérica categoría de los derechos sociales, parece que en ellos predomina el aspecto objetivo sobre el subjetivo.

Robert Alexy (1997), en una de las elaboraciones doctrinales más interesantes en torno a la naturaleza y estructura de los derechos fundamentales, explica que las normas constitucionales que contienen derechos sociales tienen la estructura de los principios.

Recordemos, brevemente, que para Alexy los principios "son normas que ordenan que algo sea realizado en la mayor medida posible, dentro de las condiciones jurídicas y reales existentes. Por lo tanto, los principios son mandatos de optimización que están caracterizados por el hecho de que pueden ser cumplidos en distinto 
grado y que la medida debida de su cumplimiento no sólo depende de las posibilidades reales sino también jurídicas. El ámbito de las posibilidades jurídicas es determinado por los principios y reglas opuestas" (1997, p. 86). Por el contrario, las reglas son normas que se cumplen o no se cumplen. Son mandatos definitivos, determinados, concretos tanto en lo fáctico como en lo jurídico. Las reglas no admiten ponderación ni la necesitan. Entre principios y reglas hay, por tanto, una diferencia cualitativa (1997, p. 87).

Si los derechos sociales responden a la estructura de los principios esto significa que no se puede establecer un modelo definitivo de los mismos, ya que dependen de los condicionantes jurídicos y económicos, lo que obliga al intérprete a ponderar, en cada caso concreto, si la provisión de determinadas prestaciones entra o no en colisión con otros principios constitucionales. Son normas de carácter indeterminado "aunque la indeterminación no sea una característica exclusiva de los derechos sociales", son derechos prima facie cuyo contenido específico se concretará mediante la ponderación con otros principios. La ponderación consiste, básicamente, en establecer entre los distintos principios una relación de precedencia condicionad ${ }^{21}$.

Dos de las objeciones más invocadas en contra de los derechos sociales son su elevado coste económico y la justiciabilidad deficiente. Frente a la primera objeción, Alexy afirma que el carácter gravoso de estos derechos no puede implicar su inexistencia. Además, todos los derechos fundamentales, en mayor o menor medida, limitan la competencia presupuestaria del legislador que no es absoluta. En cuanto a la justiciabilidad deficiente, responde el autor que este es un problema que también afecta a los derechos fundamentales tradicionales. Añade que la existencia de un derecho no puede depender sólo de su justiciabilidad (Alexy, 1997, p. 495 y sigs.).

\subsection{El problema del quantum de los derechos sociales. La cuestión de la irreversibilidad de las conquistas sociales}

Tras la crisis económica de la década de los setenta del siglo XX se adoptaron por los gobiernos occidentales una serie medidas dirigidas a restablecer el mercado como instrumento adecuado para el funcionamiento de la producción y distribución de bienes y servicios. Sin embargo, el neoliberalismo no ha producido ni la riqueza, ni el bienestar, ni la estabilidad que se proponía como objetivos. El Estado social tuvo que intervenir para intentar paliar los efectos negativos provocados por el mercado generando para ello un gasto desorbitado. El sector público se había

$21 \quad$ La propuesta de Robert Alexy (1997) para establecer qué derechos sociales fundamentales son definitivos se basa en la ponderación entre principios: el principio de libertad fáctica, el principio de la división de poderes y el de la competencia que tiene el legislador democráticamente elegido y, por último, principios materiales como la libertad jurídica de los demás, otros derechos sociales y los bienes colectivos. (Alexy, p. 494). 
convertido en una carga para el sector privado y el desmantelamiento del denominado Estado del bienestar se perfiló, desde la perspectiva neoliberal, como la única solución para salir de la crisis económica, poniendo en peligro el Estado social, en un intento por deslegitimar sus instituciones. De esta manera, se ha abonado el terreno para poner en marcha reformas estructurales, que tienen como objetivo la privatización de los servicios y bienes públicos y la reducción de la calidad y cantidad de las prestaciones sociales ${ }^{22}$.

Ahora bien, frente a estos planteamientos voces autorizadas, como la de Konrad Hesse (1983, p. 53 y 54), han defendido la irreversibilidad de las conquistas sociales, aunque con diversos matices. Para el autor alemán si bien resulta imposible deducir de la propia Constitución el contenido sustantivo de las obligaciones sociales del Estado, una vez que ha tenido lugar la regulación legal o reglamentaria, toda medida regresiva que afecte el contenido esencial de las regulaciones establecidas será contraria a la Constitución.

Böckenförde (1993, p. 78) señala que cuando sobre la base de los derechos sociales se hayan originado determinadas pretensiones mediante la intervención del legislador o la práctica administrativa, aquellas pueden ser acogidas constitucionalmente y protegidas contra su supresión definitiva. En este sentido los derechos sociales actúan como límites elementales a la transformación o supresión de las mismas, pero no prohíben su modificación o reducción compatible con el mandato social de configuración. Igualmente Offe afirma que el Estado social es un realidad irreversible: allí donde se ha instaurado y se ha consolidado difícilmente se podría desmantelar sin que, contemporáneamente, se trasformase radicalmente la estructura política y $\operatorname{social}^{23}$.

Entre la doctrina española por ejemplo López Guerra (1983, p. 348) es de la opinión que los niveles de protección reconocidos a determinados sectores sociales,

22 Así lo entiende, entre otros, M. castells, (1996). La literatura sobre las causas, consecuencias y alternativas a la crisis del Estado social es muy extensa. Para una aproximación a esta cuestión pueden consultarse los siguientes trabajos: C. De Cabo Martín La crisis del estado social, (1986) y del mismo autor "Democracia y Derecho en la crisis del Estado Social", (1994); R. Cotarelo, Del estado del bienestar al estado del malestar: la crisis del estado social y el problema de legitimidad, (1986); R. Muñoz de Bustillo et al. Crisis y futuro del estado de bienestar, (1993); R. Mishra, El estado de bienestar en la sociedad capitalista: políticas de desmantelamiento y conservación en Europa, América del Norte y Australia (1994); A. J. Porras Nadales "La evolución del Estado social y sus perspectivas", (1994, p. 231 a 245). Así mismo, pueden consultarse los números monográficos publicados en 1996 por la revista Temas para el debate dedicados a El futuro del Estado del Bienestar (num. 24) y El fracaso del neoliberalismo (núm. 25).

23 Contradicciones en el Estado del Bienestar (1990, p. 141).compete la autoorganización de la sociedad y la resolución de sus contradicciones y conflictos, su responsabilidad para cumplir con el principio social sólo alcanzará hasta ahí donde lleguen los recursos disponibles de la sociedad a la que pertenece. (1983, p. 86). 
por medio de las instituciones como la seguridad social, la legislación laboral, etc., son pasos hacia una meta futura, $\mathrm{y}$, por ello, podrán ser modificados únicamente en sentido favorable a los afectados, según las previsiones constitucionales. En este sentido, según el autor, la Constitución se pronuncia a favor de la irreversibilidad de las medidas del progreso social.

En torno a esta cuestión nos parece de sumo interés el planteamiento que hace Parejo Alfonso (1983, p. 84 y sgs). Tras afirmar que el Estado social es un principio jurídico ligado a la intervención estatal en la vida social, económica, y cultural que crea una serie de obligaciones dirigidas a los poderes públicos competentes para asegurar la eficacia de los valores constitucionalizados, reconoce, sin embargo que su consistencia es reducida.

En primer lugar, porque aunque el Tribunal Constitucional, en base al principio del Estado social, pueda rechazar una medida legislativa o de cualquier otro poder público que no cumpla con el deber de configuración social, no obstante, no facilita, según palabras textuales del propio autor, el sustrato necesario para valorar la suficiencia del cumplimiento del principio y su corrección constitucional. En segundo lugar, porque del principio del Estado social no se pueden deducir directamente derechos del ciudadano a su efectivo cumplimiento (Parejo, 1983, p. 84) ${ }^{24}$.

Lo que sí es posible, afirma Parejo Alfonso (1983, p. 85-86), es elaborar desde la propia Constitución una aproximación al contenido sustantivo del principio del Estado social. En primer lugar, aunque en la Constitución no se establezca un modelo económico concreto, sí se diseña un esquema de límites jurídicos, objetivos y determinables, que acotan el poder de configuración social del legislador. La "ambigüedad" 25 del orden económico no es un reflejo de la incapacidad de la propia Constitución para definir el Estado social. Al contrario, la adaptabilidad de este último a las necesidades cambiantes "siempre en el marco del sistema axiológico de la Constitución representado por la dignidad humana, fruto de la igualdad y de la justicia” es una característica del Estado social. Lo que sí es constante es la exigencia constitucional de alcanzar la mayor igualdad real y efectiva posible de los ciudadanos en cada momento (Parejo, 1983, p. 86).

${ }_{24}$ Explica Parejo cómo desde esta perspectiva sí se entiende la postura de la doctrina alemana que considera que los objetivos sociales del Estado no se pueden convertir en derechos porque dependen de la disponibilidad económica que exista en cada momento. La realización del principio del Estado social no es inmediata y plena, sino histórica y relativamente factible. Si al Estado le compete la autoorganización de la sociedad y la resolución de sus contradicciones y conflictos, su responsabilidad para cumplir con el principio social sólo alcanzará hasta ahí donde lleguen los recursos disponibles de la sociedad a la que pertenece. (1983, p. 86).

25 El entrecomillado es del propio Parejo Alfonso. 
En segundo lugar, aunque el legislador tenga un amplio margen de discrecionalidad para configurar el principio del Estado social, sin embargo, en nuestro sistema jurídico los principios del Capítulo III del Título I de la Constitución española son, como explica Parejo Alfonso (1983, p. 87), criterios vinculantes que han de estar presentes en el proceso de desarrollo y aplicación de la Constitución. Estos principios tienen un efecto directo que se traduce en el deber del Estado de hacerlos efectivos y en la necesaria adecuación de las normas y actos de los poderes públicos a los mandatos constitucionales. Por lo tanto, a través de la legislación de desarrollo se concreta y cristaliza el principio del Estado social en la materia correspondiente.

En este punto de la argumentación el autor se formula la siguiente pregunta: una vez que los derechos sociales se concretan por la legislación ordinaria, ¿se constitucionalizan en virtud del principio del Estado social? O, formulada la pregunta en otros términos ¿son irreversibles las conquistas sociales alcanzadas? (Parejo, 1993 , p. 89 y sig) ${ }^{26}$

Para empezar, Parejo rechaza el uso de expresiones como "reversibilidad" o "irreversibilidad" y prefiere recurrir a los términos de "reducción", "supresión" o "transformación", según los casos. Cualquier medida que pretendiese reducir o suprimir los derechos sociales sería inconstitucional por colisionar con las que él denomina directivas constitucionales definitorias de los fines del Estado (artículos $1.1^{\circ} \mathrm{CE}, 9.2^{\circ} \mathrm{CE}, 10.1^{\circ} \mathrm{CE}$ y Capítulo III del Título I).

La escasa jurisprudencia constitucional sobre esta cuestión ha establecido que " [...] no puede privarse al trabajador sin razón suficiente para ello de las conquistas sociales ya conseguidas" 27 . Por lo tanto, en el marco de la Constitución sólo sería posible una transformación del ordenamiento social llevada a cabo por una nueva política socio-económica que sea respetuosa con los principios y con el orden constitucional $^{28}$.

En todo caso, Parejo Alfonso (1983, p. 90) descarta la irreversibilidad del desarrollo legislativo de los derechos sociales, porque afirmar lo contrario vulneraría el valor del pluralismo político que se deriva del reconocimiento constitucional de uno de los tres pilares del Estado: el principio democrático: "el principio social no puede

26 Esta cuestión fue de nuevo abordada por Parejo Alfonso, en "El Estado Social Administrativo: algunas reflexiones sobre la crisis de las prestaciones y servicios Públicos", (2000, p. 224 a 230 ).

27 STC 81/1982, de 21 de diciembre, F.J. $3^{\circ}$.

28 El "orden" del orden constitucional, como así lo denomina Parejo Alfonso (2000, p. 227 a 229), es el límite infranqueable por el legislador ordinario cuando lleve a cabo reformas sobre conquistas sociales por él establecidas. El orden constitucional está presidido por el valor de la dignidad de la persona en una dimensión integral en la que, necesariamente, está involucrado el valor de la solidaridad y los bienes y fines constitucionales con el relacionados que se consagran en el Capítulo III del Título I CE. 
reclamar, por tanto, una validez que anule, no ya su sumisión al derecho, sino tampoco el de democracia y su concreción inmediata en el pluralismo político, que tiene como esencia precisamente la posibilidad de alternancia de opciones políticas (incluso y principalmente en el plano socioeconómico) en el marco de la Constitución." Además, entre Constitución y Ley no media una relación de ejecución, sino de desarrollo. La legislación ordinaria concretiza el orden constitucional sobre las bases reales de los recursos económicos y financieros disponibles en cada momento ${ }^{29}$. Desde esta perspectiva, no puede considerarse que nuestra Constitución admita la existencia de verdaderos iura quaesita (Parejo, 2000, p. 227).

Estas conclusiones de carácter general deben ser matizadas como apunta el propio Parejo Alfonso (2000, p. 91), ya que no todos los principios del Capítulo III del Título I de la Constitución española tienen la misma contextura y consistencia. Puede ocurrir que en algunos casos nos encontremos en la Constitución con decisiones materiales precisas, como es el caso de las garantías institucionales, que van más allá del ámbito de los principios y que limitan el poder transformador del legislador. La trasgresión de esas decisiones materiales, en virtud de la eficacia directa del orden constitucional, conllevaría la inconstitucionalidad de las medidas legislativas adoptadas.

Entre esas decisiones materiales se encuentra el artículo $43 \mathrm{CE}$ que consagra un derecho prestacional, el derecho a la asistencia sanitaria y una institución garantizada constitucionalmente, el Sistema Nacional de Salud. Como ha señalado Navarro Munuera (1996), los poderes públicos ostentan una amplia discrecionalidad a la hora de organizar esta institución. Sin embargo, existen una serie de límites tanto en la estructuración del Sistema Nacional de Salud, como en la concreción de las prestaciones sanitarias. En cuanto a la vertebración del servicio de tutela de la salud deberá responder a un verdadero sistema, a una organización sanitaria basada en pautas de unidad, armonía, coherencia y coordinación, respetando, al mismo tiempo, el principio constitucional de autonomía. Por lo que se refiere al establecimiento de las prestaciones, se deberá garantizar un nivel prestacional mínimo y la irreversibilidad del contenido esencial del derecho a la asistencia sanitaria. La cuestión es cómo establecer el contenido prestacional mínimo protegido por la Constitución, respetando el principio democrático y el principio del Estado social.

\footnotetext{
29 Así también lo ha entendido el Tribunal Constitucional por ejemplo en la STC 65/1987, de 21 de mayo, en la que tras afirmar que el objetivo de la Seguridad Social es reducir o eliminar situaciones de necesidad mediante asistencia y prestaciones sociales suficientes, señala que corresponderá al legislador apreciar la importancia relativa de las situaciones de necesidad a satisfacer y regular el nivel y condiciones de las prestaciones a efectuar o modificarlas para adaptarlas a las condiciones de cada momento.
} 
El derecho a la asistencia sanitaria es lo que denominaría Robert Alexy un derecho prestacional en sentido estricto. Un derecho frente al Estado para que éste cree y organice un conjunto de servicios sanitarios. Ahora bien, dado que los medios materiales y humanos son limitados y puesto que existen otros principios o bienes constitucionales que también deben ser protegidos, los poderes públicos dispondrán de un margen de actuación dentro del cual podrán moverse para fijar el contenido definitivo del derecho a la asistencia sanitaria. No obstante, recuerda Alexy (1997, p. 494 y sig.) que la importancia de los derechos sociales es tal que su concesión no puede dejarse sin más en manos de la mayoría parlamentaria. Los derechos sociales pueden estar sometidos a restricciones, pero, éstas han de ser proporcionadas. ¿Cómo dilucidar si una restricción de un derecho social es desproporcionada y, por lo tanto, inconstitucional? Para contestar a este interrogante se recurre a la figura alemana del principio de prohibición de protección deficiente cuya estructura es muy similar a la del principio de proporcionalidad como prohibición de exceso aplicable a los derechos de defensa.

Los derechos a prestaciones, y por tanto el derecho a la asistencia sanitaria, son, aplicando la construcción teórica de Alexy, mandatos de optimación. Esto es, el individuo tiene un derecho prima facie $^{30}$ a todos los medios materiales necesarios para hacer efectivo su derecho a la asistencia sanitaria. No obstante, este máximo no se puede exigir al Estado si existen otros principios constitucionales o impedimentos materiales que lo imposibiliten. Siendo así, cada derecho tendría un doble contenido. En primer lugar, un contenido prima facie del que formarían parte todos los medios indispensables para cubrir la necesidad básica, en nuestro caso la salud, amparada por el ámbito normativo del derecho y, en segundo lugar, un contenido definitivo integrado por aquellas posiciones jurídicas oponibles al legislador y a la Administración Pública que no pueden ser restringidas porque así lo determina el principio de prohibición de protección deficiente.

Para explicar la prohibición de protección deficiente de los derechos sociales, se han de utilizar los subprincipios de idoneidad, necesidad y proporcionalidad. Estos tres subprincipios, como ha señalado el jurista colombiano Bernal Pulido (2004, p.141), al que seguiremos de aquí en adelante, son un criterio estructural cuya aplicación permitirá determinar el contenido de estos derechos y establecer si existe o no vulneración de los mismos por omisión total o parcial en la actuación de los poderes públicos. De este modo, si el Estado dejara arbitrariamente de facilitar determinadas prestaciones sanitarias estaríamos ante una omisión inconstitucional, a no ser que su actuación estuviese justificada por las exigencias de cumplir los

30 Para una aproximación al concepto de los derecho prima facie véase BErnal Pulido, (2003, p. 615 y sigs.) 
subprincipios de idoneidad, necesidad y proporcionalidad. Desatender el derecho a la asistencia sanitaria sería inconstitucional a no ser que esta omisión estatal se justificase por la necesidad de atender otros principios constitucionales, como por ejemplo podría ser el derecho a la educación. Pero, no basta con cumplir el requisito de la idoneidad. También es preciso que las omisiones, para ser constitucionalmente admisibles, se adecuen al sub principio de necesidad, según el cual una omisión sería inconstitucional, piénsese por ejemplo en la supresión de una determinada prestación de la cartera de servicios sanitarios, si existiese otra medida alternativa que favoreciese el fin constitucional legítimamente perseguido y permitiese una mayor realización del derecho social. Finalmente, estaremos ante una protección deficiente y, por lo tanto, inconstitucional cuando aun existiendo un fin legítimo que justifique tal omisión, los beneficios que se deriven para ese fin no compensen los sacrificios que la no satisfacción de derecho social implica.

Por ejemplo, sería inconstitucional el incremento de la partida del gasto en educación, en detrimento del gasto sanitario, si la mejora para el sector educativo fuera mínima en comparación a los perjuicios que se derivan para la asistencia sanitaria.

Ahora bien, a pesar de la prohibición de protección deficiente, el legislador y la Administración dispondrían, como señala Alexy en el Epílogo a su Teoría (2002, p. 23 y sig.), de cierto margen de acción estructural y epistémico. Respecto a su acción estructural, el legislador tiene libertad para fijar los fines, los medios e incluso dispone de margen para la ponderación, sobre la base de los subprincipios más arriba enunciados. Así mismo, el legislador dispone de un margen de acción epistémico basado en el principio democrático y en la división de poderes. De esta manera se garantiza que el juez constitucional no se entrometa en la tarea legislativa de configuración en aquellos supuestos en los que existan dudas sobre cuál de las posibles medidas fácticas o normativas sea la más beneficiosa para la efectividad del derecho (Alexy, 2002, p. 49 y sig.).

\section{A modo de conclusión: el derecho a la protección de la salud como ejemplo de superación de la tradicional fractura entre los derechos de libertad y los derechos sociales}

El reconocimiento del derecho a la protección de la salud en las Constituciones contemporáneas representa la culminación de un largo proceso que se inició hace ya más de dos siglos. Desde la asistencia sanitaria benéfica, pasando por los seguros de enfermedad obligatorios de inspiración bismarckiana, se ha llegado, finalmente, a la consagración a nivel constitucional de uno de los derechos más característicos del constitucionalismo social contemporáneo. El derecho a la protección de la salud es, sin lugar a dudas, uno de los derechos sociales por antonomasia. 
Derecho y Realidad

El proceso de positivación del derecho a la protección de la salud, primero en la legislación ordinaria y más tarde en los textos constitucionales, ha sido simultáneo al proceso de gestación y consolidación del Estado social. La transformación del contenido y de la naturaleza jurídica de este derecho se ha producido paralelamente a la asunción de nuevas funciones por parte del Estado. Así mismo, cuando el Estado social ha entrado en crisis, uno de los primeros sectores que se ha visto amenazado por el desmantelamiento del sistema prestacional ha sido, precisamente, el sanitario.

Pero, además, la singularidad del derecho a la protección de la salud estriba en ser el ejemplo más claro de la superación de la fractura que, tradicionalmente, se había establecido entre las libertades individuales y los derechos sociales. En este sentido la propia Constitución italiana de 1947 se refiere al diritto alla salute como un diritto fondamentale dell'individuo.

Recurriendo a la expresión acuñada por el tantas veces citado Alexy (1997, p. 240), el derecho a la protección de la salud es "un derecho fundamental como un todo", es decir un haz de posiciones individuales iusfundamentales. Sin embargo, su ubicación en el capítulo de la Constitución de 1978 dedicado a los Principios rectores de la política social y económica ha contribuido negativamente a la hora de relegarlo a la genérica categoría de los derechos sociales, con todo lo que ello implica desde el punto de vista de su eficacia y de su tutela jurídica. Sin embargo, una obligada relectura de los textos constitucionales a la luz de las nuevas teorías sobre los derechos fundamentales nos lleva a concluir que estamos ante una figura jurídica compleja y no ante un simple derecho social.

La apertura semántica y estructural que han experimentado los derechos fundamentales afecta también al derecho a la protección de la salud. Ahora bien, esto dificulta, en gran medida, la tarea de establecer cuál es su contenido. Y ello por dos razones. En primer lugar, porque el mismo concepto de salud está sometido a continuos cambios. Es un concepto dinámico, que no se puede identificar exclusivamente con la ausencia de enfermedad, y que varía según evoluciona el estado de la ciencia. Por otro lado, la salud entronca directamente con otros bienes jurídicamente protegidos, como pueden ser la vida o la integridad personal, que en ocasiones se solapan con la salud. En segundo lugar, tanto la doctrina como la jurisprudencia han subrayado que los preceptos constitucionales en torno a los cuales se articulan la regulación constitucional de esta materia, revela su estructura compleja.

Dicho esto, podemos afirmar que el derecho a la protección de la salud tiene un marcado carácter multifuncional: asegura la libertad y la autodeterminación personal con relación a la salud; ordena el establecimiento y conservación de determinadas 
estructuras organizativas públicas para garantizar el cumplimiento del mandato constitucional establecido en el artículo $9.2^{\circ} \mathrm{CE}$ e impone su protección jurídica, no sólo en las relaciones con los poderes públicos, sino también entre particulares, lo que conlleva un desarrollo de la vertiente subjetiva del derecho y de los mecanismos jurídicos de tutela desde la perspectiva del derecho ordinario (administrativo, civil, laboral, penal) y del derecho constitucional.

\section{Referencias}

Abendroth, W. (1973). Sobre el concepto de Estado de derecho democrático y social tal como se formula en la Constitución de la República Federal de Alemania. En Sociedad antagónica y democracia política. Ensayos sobre sociología política. M. Sacristán (trad.). (p. 266). Barcelona-México: Grijalbo.

Abendroth, W. (1986). El Estado de derecho democrático y social. En W. Abendroth, E. Forsthoff \& K. Doehring. El Estado social. (p. 19 y 20). Madrid: Centro de Estudios Constitucionales.

Alexy, R. (1997). Teoría de los derechos fundamentales. Madrid: Centro de Estudios Constitucionales.

Alexy, R. (2002). Epílogo a la teoría de los derechos fundamentales. Revista Española de Derecho Constitucional, (66), 23 y sigs.

Baldassarre, A. (1989). Voz "Diritti social”. En Enciclopedia Giuridica Treccani, Vol. XI, (p. 28 y sigs.). s.l.: s.n.

Baldassarre, A. (1997). En G. Giappichelli (Editore). Diritti della persona e valori costituzionali. (p. 123-222). Torino: s.n.

Benda, E. (1996). El Estado social de derecho. En Benda et al. Manual de derecho constitucional, (p. 521 y sigs.). Madrid: IVAP-Marcial Pons.

Bernal, C. (2003). El principio de proporcionalidad y los derechos fundamentales: el principio de proporcionalidad como criterio para determinar el contenido de los derechos fundamentales vinculante para el legislador. Madrid: Centro de Estudios Constitucionales.

Bernal, C. (2004). Fundamento, concepto y estructura de los derechos sociales. Una crítica a “Existen derechos sociales?” de Fernando Atria. Discusiones, (4), 141.

Böckenförde, E. (1993). Sobre la situación de la dogmática de los derechos 
fundamentales tras 40 años de Ley Fundamental. En Escritos sobre Derechos Fundamentales, (p. 101 y sig.). Baden-Baden: Nomos Verlagsgesellschaft.

Böckenförde, E. (1993). Teoría e interpretación de los derechos fundamentales. En Escritos sobre derechos fundamentales. (p. 44-71). Baden-Baden: Nomos Verlagsgesellschaft.

Carmona, C. (2000). El Estado social de derecho en la constitución. Madrid: CES.

Cascajo, J.L. (1979). El problema de la protección de los derechos fundamentales. En Los derechos humanos. Significación, estatuto jurídico y sistema. (p. 275). Sevilla, España: Publicaciones de la Universidad de Sevilla.

Cascajo, J.L. (1988). La tutela constitucional de los derechos sociales. Madrid: Centro de Estudios Constitucionales.

Cascajo, J.L. (1992). La voz "Estado social y democrático de derecho": materiales para un léxico constitucional español. Revista del Centro de Estudios Constitucionales, (12), 9 y sigs.

Castells, M. (1996). El futuro del Estado del bienestar en la sociedad informal. Sistema, (131).

Corso, G. (1981). I diritti sociali nella costituzione italiana. Rivista Trimestrale di Diritto Pubblico, 759 y sigs.

Cossio, J.R. (1989). Estado social y derechos de prestación. Madrid: Centro de Estudios Constitucionales.

Cotarelo, R. (1986). Del Estado del bienestar al Estado del malestar: la crisis del Estado social y el problema de legitimidad. Madrid: Centro de Estudios Constitucionales.

De Cabo, C. (1986). La crisis del Estado social. Barcelona: PPU.

De Cabo, C. (1994). Democracia y derecho en la crisis del Estado social. Sistema, (118-119).

De Cabo, C. (1994). Estado social de derecho y ley general: una perspectiva general. Jueces para la democracia, (23), 35 y sigs.

De Cabo, C. (2006). Teoría constitucional de la solidaridad. Barcelona: Marcial Pons.

Díaz, E. (1988). Estado de derecho y sociedad democrática ( $8^{\mathrm{a}}$ ed., $6^{\mathrm{a}}$ reimp.). Madrid: Taurus.

Forsthoff, E. (1975). El Estado de la sociedad industrial. El modelo de la República Federal de Alemania. L. López \& J.N. Muñiz (trad.). Madrid: Instituto de 
Estudios Políticos.

Forsthoff, E. (1986). Problemas constitucionales del Estado social. En W. Abendroth, E. Forsthoff \& K. Doehring. El Estado social. (p. 47 y 48). Madrid: Centro de Estudios Constitucionales.

Forsthoff, E. (1986). Concepto y esencia del Estado social de derecho. En W. Abendroth, E. Forsthoff \& K. Doehring. El Estado social. Madrid: Centro de Estudios Constitucionales.

García, J. (1990). Del Estado del bienestar al Estado del malestar. (2 ${ }^{\text {a }}$ ed.). Madrid: Centro de Estudios Constitucionales.

García, R. (1992). Las aporías de los derechos fundamentales y el derecho a una vivienda. Madrid: Instituto de estudios de la Administración Local.

García-Pelayo, M. (1985). Estado contemporáneo (2ª ed.) Madrid: Alianza.

Garrorena, E. (1987). El Estado español como Estado social y democrático de derecho. Tecnos, 1987, $1^{\mathrm{a}}$ ed ( $1^{\mathrm{a}}$ reimp.),

Giannini, M.S. (1977). Stato sociale: una nozione inutile. En Scritti in onore di $C$. Mortati, vol. I. (p. 139-165). Italia: Giuffrè.

Gomes, J. (1998). Metodología "fuzzy" y "camaleones normativos" en la problemática actual de los derechos económicos, sociales y culturales. Derechos y libertades: Revista del Instituto Bartolomé de las Casas, (6), 35 y 36.

Häberle, P. (2003). La garantía del contenido esencial de los derechos fundamentales. J. Brage (trad.). Madrid: Dykinson.

Hesse, K. (1978). Grunzüge des Verfassungsrechts der Bundesrepublik Deutschland. ( $11^{\mathrm{a}}$ ed.). Heidelberg und Karlsruhe: C.F. Müller.

Hesse, K. (1996). Significado de los derechos fundamentales. En Benda et al. Manual de derecho constitucional, (p. 86). Madrid: IVAP-Marcial Pons.

López, L. (1983). Régimen constitucional español. Vol.I. Barcelona: Labor.

Luciani, M. (1980). Il diritto costituzionale alla salute. En Diritto e società, (p. 771 y sigs.). s.1.: s.n.

Luciani, M. (1991). Salute (diritto alla salute- Dir. Cost.). En Enciclopedia Giuridica Treccani, (p. 3 y 4). S.1.: s.n.

Luciani, M. (1994). Sui diritti sociali. En R. Romboli, La tutela dei diritti davanti alle Corti costituzionali, (p. 99 y sig). Torino: Giappichelli.

Mazziotti, M. (1964). Diritti social. En Enciclopedia del Diritto. (p. 804 y sigs). Milano: Giuffrè. 
Mishra, R. (1994). El estado de bienestar en la sociedad capitalista: políticas de desmantelamiento y conservación en Europa, América del Norte y Australia. J. Alonso (trad.). Madrid: Ministerio de Asuntos Sociales.

Muñoz, R. et al. (1993). Crisis y futuro del Estado de bienestar. Madrid: Alianza.

Navarro, M. (1996). Bioética y Ley General de Sanidad. En M. Casado (ed.). Materiales de bioética y derecho. Barcelona: Cedecs.

Pace, A. (1998). La heterogénea estructura de los derechos constitucionales. Cuadernos de Derecho Público, (5), 20 y sigs.

Parejo, L. (1983). El Estado social administrativo: algunas reflexiones sobre la crisis de las prestaciones y servicios Públicos. Revista de Administración Pública, (153), 224 a 230.

Parejo, L. (1983). Estado social y administración pública. Madrid: Civitas.

Parejo, L. (1983). Estado social y administración pública. Los postulados constitucionales de la reforma administrativa. Madrid: Civitas.

Pérez, A.E. (1984). Los derechos fundamentales. Madrid: Tecnos.

Pezzini, B. (2001). La decisione sui diritti sociali. Indagine sulla struttura costituzionale dei diritti social. Italia: Giuffrè.

Porras, A. J. (1994). La evolución del Estado social y sus perspectivas. Sistema, (118-119), 231 a 245. 